\title{
NOMENCLATURE AND TRANSLITERATION
}

ll Chinese names in this study are transliterated with pinyin, with
some exceptions. Chinese names and terms familiar to Western
readers, such as Chiang Kai-shek, Sun Yat-sen, and Kuomintang, are not converted into their pinyin forms (Jiang Jieshi, Sun Yixian, and Guomindang).

Most of the Tibetan personal names in this study are from Chinese texts. Their transliterations, if known, are done with the THL Extended Wylie Transliteration Scheme (EWTS). If the romanized form of a Tibetan personal name cannot be ascertained, italicized pinyin is used to indicate its Chinese pronunciation, followed by Chinese characters in parentheses.

Most geographic names in the Tibetan areas, if ascertainable, appear in their transliterated Tibetan forms followed by Chinese forms in parentheses. If a location's Tibetan name cannot be ascertained, its Chinese name, italicized, is used. The most difficult cases involve geographic names, which, depending on their users, mean rather different areas. For instance, in any discussion pertinent to Tibet, the name of the region itself is a disputed subject. "Tibet" and its corresponding Chinese term Xizang (西藏) mean rather different areas when used by the PRC authorities and the Tibetan government in exile. The PRC authorities use Tibet/Xizang to refer to the area of the current Tibetan Autonomous Region (TAR), which is largely congruent with the political domain of the traditional Tibetan government, or Kashag, before 1959. In contrast, the Tibetan authorities in Dharamshala use "Tibet" to mean a much larger area populated by ethnic Tibetans, including not only Ü-Tsang 
and Ngari of the TAR but also Kham (Kang) and Amdo (Anduo) in today's Qinghai, Gansu, Sichuan, and Yunnan provinces of the PRC. Because this study is a focused analysis and narrative of the Chinese Communist Party's policy conceptions and practices with respect to Tibet, to avoid confusion, this study follows the usage of "Tibet" in the Chinese primary sources. In the 1950s, in Beijing's policy directives and the CCP's internal discussions, Xizang, or Tibet, was used as a noun to refer unmistakably to the political and territorial domain under the fourteenth Dalai Lama.

Meanwhile, the adjective "Tibetan"-as in "Tibetan areas" (Zangqu), "Tibetan population" (Zangmin), and "Tibetan nationality" (Zangzu)—carries a broader ethnographic meaning beyond the limits of Lhasa's political power. Confusion, however, cannot be avoided completely, and specific explanations are provided wherever necessary.

Finally, all Chinese titles of documents and scholarly articles in the notes are translated but not transliterated. This practice is open to criticism in the field but is used solely for reducing the bulkiness of the citations. 
TO THE

END OF

REVOLUTION 
